Estudios Constitucionales, Año 17, № 2, 2019, pp. 141-162

ISSN 07180195

Centro de Estudios Constitucionales de Chile Universidad de Talca

"Ni rebelión ni autoritarismo judicial. Una defensa

del control de la constitucionalidad de la jurisprudencia"

Rodrigo Camarena González

\title{
NI REBELIÓN NI AUTORITARISMO JUDICIAL. UNA DEFENSA DEL CONTROL DE LA CONSTITUCIONALIDAD DE LA JURISPRUDENCIA
}

\author{
Neither judicial rebelion nOR aUthoritarism. A Defense of \\ Consitutional Review on Precedents
}

\author{
Rodrigo CAMAREna GonZÁlez* \\ ITAM, México \\ rodrigo.camarena@itam.mx
}

RESUMEN: Desde el Derecho Comparado, se hace un análisis y una defensa del control de la constitucionalidad de la jurisprudencia. Se sostiene que este tipo de control es razonable, excepcionalmente, si se entiende la jurisprudencia como reglas prima facie protegidas por los principios formales de competencia, igualdad, certeza y jerarquia, no como reglas estrictas sustentadas solo en el principio de jerarquia, como la Suprema Corte mexicana las ha entendido.

ABSTRACT: From the perspective of Comparative Law, the paper argues in favor of constitutional review on precedents. It claims that this type of review is reasonable in exceptional circumstances if precedents are understood as prima facie rules that safeguarded by the formal principles of competence, equality, certainty and hierarchy. Not as strict rulse grounded only in the principle of hierarchy, as the Mexican Supreme Court has understood them.

PALABRAS CLAVE: Control de la constitucionalidad, jurisprudencia, precedente, normas adscritas.

KEY WORDS: Constitutional review, jurisprudence, precedent, ascribed noms.

\section{INTRODUCCIÓN}

El objetivo del presente artículo es doble. Por un lado, busca aclarar la naturaleza del control de la constitucionalidad de la jurisprudencia. En este control no se revisa la constitucionalidad de las disposiciones legislativas en sí mismas, sino la interpretación judicial vinculante que se les adscribe a ellas. Por otro

\footnotetext{
* Profesor de tiempo completo del Departamento de Derecho del ITAM. Doctor en Derecho por la Universidad Macquarie (Sidney, Australia), Master of Jurisprudence por la Universidad de Sídney y Licenciado en Derecho por la Universidad de Guadalajara, México. Agradezco a la Asociación Mexicana de Cultura, A.C. por su generoso apoyo a esta investigación. Gracias a Mariana Ortega por su ayuda y a los integrantes del Tequila Seminar por sus sugerencias, críticas y sugerencias.
}

Artículo recibido el 27 de junio de 2019, probado el viernes 15 de noviembre de 2019. 
lado, busca defender el control de la constitucionalidad en el entendido de que ninguna fuente debe estar exenta de revisión constitucional.

Aunque este tipo de control ha tenido lugar en diversos países de la tradición civilista como Francia ${ }^{1}$, Colombia y México, su análisis, desde el derecho comparado, es escaso. No obstante, su estudio es relevante desde las perspectivas analítica y normativa. Analíticamente, es importante entender qué es precisamente lo que se está controlando y qué distingue la interpretación judicial de la labor legislativa. Normativamente es relevante dar argumentos sobre si este control debe, o no, ser aceptado en un estado constitucional. Este análisis contribuye, por un lado, a la discusión sobre los distintos tipos de control de la constitucionalidad. Sea que un tribunal amplié su poder concentrado para controlar jurisprudencia ordinaria ${ }^{2}$, otros órganos judiciales se consideren competentes para realizar el control difuso sobre jurisprudencia de la corte suprema, o se genere alguna clase de diálogo entre órganos ${ }^{3}$. Por otro lado, el análisis contribuye al revivido debate acerca de la naturaleza del precedente o jurisprudencia como fuente jurídica en la tradición civilista ${ }^{4}$.

Este artículo se concentra en el caso del control de la constitucionalidad de la jurisprudencia en México y Colombia. Este trabajo no analiza otras técnicas argumentativas legítimas para no seguir un precedente constitucional sin declararlo inconstitucional, como la distinción de $\operatorname{casos}^{5}$, sino que se concentra en la posible inaplicación o invalidación de la jurisprudencia por considerarla inconstitucional. Tanto la Suprema Corte mexicana (SCJN) como la Corte Constitucional Colombiana (CCC) han abordado este tema. Además, ambas han distinguido entre textos (disposiciones) y la interpretación que se les adscribe (normas) para destacar la labor creativa del intérprete judicial. Sin embargo, los diseños institucionales son distintos. El control abstracto es de acceso universal en Colombia, mientras que, en México excluye a los particulares, quienes deben

1 Véase, por, ejemplo, Francia, Consejo Constitucional, Sentencia 2010-39 QPC de 6 de octubre de 2010. Cfr. BÉaL-Long (2016).

2 Kelsen (1942).

3 Bushell y Hogg (1997); Tushnet (2003); Gardbaum (2002). No obstante, véase, Dixon (2012) (donde argumenta que la facultad de "revocación" (override) de las decisiones judiciales por el legislativo se ha utilizado muy poco en la práctica, por lo que en realidad no ha habido tanto diálogo como se asume.

4 Peczenik (1996); Moral (2002); (López, 2006, 2016); Serna de la Garza (2009); Barrera (2014); Sierra Sorockina (2016); Gómora Juárez (2017).

5 Véase Llewellyn (1960), pp. 84-95. 
activar el control semi-difuso a través del Juicio de Amparo o procedimientos similares ante órganos distintos a la corte. Esto hace el estudio de caso particularmente fructífero por el nivel adecuado de similitud y diferencia entre los dos sistemas.

En este contexto, ambas cortes se han preguntado ¿̇debe existir un mecanismo para revisar la constitucionalidad, no de las disposiciones legislativas, sino de la jurisprudencia? La SCJN ha rechazado el control semi-difuso que los Tribunales Colegiados -inferiores a ella- y el Tribunal Electoral realizaron en casos concretos para cuestionar su jurisprudencia. Según la SCJN, su jurisprudencia, aunque es una norma general, abstracta e impersonal, no puede estar sujeta a un control externo. Solo ella misma puede modificarla o invalidarla. En cambio, en un sistema con tres cortes supremas, la CCC ha sostenido que existe una modalidad excepcional del control abstracto de constitucionalidad para controlar la jurisprudencia de legalidad. La CCC ha disociado la interpretación judicial vinculante del Consejo de Estado de las disposiciones legislativas y la ha llegado a declarar inconstitucional.

Este tipo de control ha dado lugar a un debate judicial. Para los escépticos, este control, es una indebida expansión del control de la constitucionalidad tradicional que va encaminado a limitar al poder legislativo, no al judicial. El sistema de control concentrado de acceso ciudadano, pero con cortes supremas, como el colombiano, es un pretexto para que la Corte Constitucional expanda su poder e invada la labor jurisprudencial ordinaria. En un sistema sin control abstracto de acceso ciudadano, como el mexicano, es un pretexto para que los inferiores desafíen la jurisprudencia del superior, dejando claro que para ellos no hay órganos de cierre. En cambio, para los optimistas, si se rechaza este tipo de control, se dejaría a una fuente generada por órganos no elegidos democráticamente exenta del control de constitucionalidad. Los temores de cacofonía, rebelión o autoritarismo judicial se pueden atemperar mediante un control excepcional que cumpla con la carga de argumentación apropiada.

Para defender una postura optimista, el resto del artículo cuenta con la siguiente estructura. La sección 2 describe el estudio de caso del control de la constitucionalidad de la jurisprudencia en México y en Colombia. Después, la sección 3 reconstruye analíticamente el control a la luz de la distinción entre disposición y norma. Posteriormente, la sección 4 propone un entendimiento alternativo del control de la constitucionalidad de la jurisprudencia. La jurisprudencia es un conjunto de reglas prima facie ancladas en los principios de 
igualdad, jerarquía y certeza que puede llegar a desafiarse por violación grave principios constitucionales. El artículo concluye con los retos que este control implica para los principios formales.

\section{Los casos de México y Colombia}

\subsection{México: La imposibilidad de control por violar el principio de jerarquía}

La SCJN ha rechazado la posibilidad de que otros órganos ejerzan control de la constitucionalidad de su jurisprudencia. El rechazo ha sido absoluto. Ya sea formal, sustantivo, vertical u horizontal.

En vista del peculiar sistema mexicano de tesis jurisprudenciales, la SCJN ha rechazado el control formal de la jurisprudencia. Las tesis son la "expresión por escrito en forma abstracta de un criterio jurídico establecido al resolver un caso concreto" 6 . Es decir, las tesis son un esfuerzo por monopolizar la determinación de la ratio decidendi a través de prácticas cuasi-legislativas. Un tribunal colegiado consideró que una tesis acerca del principio de definitividad del Amparo de la segunda sala de la SCJN no correspondía con lo realmente resuelto, por lo que decidió no seguirla. En la C.T. 40/2000, la Segunda Sala afirmó que los tribunales colegiados están "imposibilitados para cuestionar el carácter, contenido y proceso de integración de una jurisprudencia”7.

El debate del control de la constitucionalidad de la jurisprudencia se revivió después de la reforma constitucional de derechos humanos de $2011^{8}$, pero ahora en cuanto al control sustantivo. La reforma estableció, entre otras cosas, la obligación de todas las autoridades de "promover, respetar, proteger y garantizar los derechos humanos", elevó a rango constitucional los tratados internacionales que incluyan derechos humanos y constitucionalizó el principio pro persona y la interpretación conforme ${ }^{9}$. Como consecuencia de esta reforma la SCJN declaró que era facultad de todos los órganos judiciales hacer un control de constitucio-

\footnotetext{
6 Suprema Corte de Justicia de la Nación, Acuerdo General 20/2013, artículo 2.A.

7 Ibídem.

8 Constitución Política de los Estados Unidos Mexicanos de 1917 (CPEUM), reforma de 10 de junio de 2011.

9 Ibídem, artículo 1.
} 
nalidad y convencionalidad ex officio de fuentes infra-constitucionales, y en su caso, desaplicar las normas que contradigan derechos humanos ${ }^{10}$.

Los órganos judiciales estaban facultados para desaplicar leyes, pero ¿estaban facultados para desaplicar la jurisprudencia de la SCJN? Para un tribunal colegiado la respuesta fue afirmativa, aun si eso implicaba un desafío al precedente vertical. En un caso de indemnización laboral por despido de miembros de seguridad pública, el colegiado desaplicó una jurisprudencia de la segunda sala. La sala interpretó una disposición constitucional que establecía que en estos casos "el Estado solo estará obligado a pagar la indemnización y demás prestaciones"11. Para darle contenido a la expresión "demás prestaciones", la Sala había resuelto que no era supletoria la Ley Federal del Trabajo -que regula relaciones laborales privadas- porque la Constitución establece que la seguridad pública es una relación administrativa, no laboral ${ }^{12}$. El colegiado consideró que la jurisprudencia era inconstitucional ya que otorgaba menos prestaciones a los trabajadores de seguridad pública que a los privados. El colegiado sostuvo que la reforma de derechos humanos obligaba a los órganos judiciales a "eliminar tecnicismos y formalismos extremos"13 y en vista del trato discriminatorio desaplicó la jurisprudencia de la SCJN.

La segunda sala reprochó este tipo de control de manera categórica. A decir de la sala, la jurisprudencia vela por el derecho a la seguridad jurídica y el control de la jurisprudencia violenta este derecho ${ }^{14}$. La sala ordenó la "supresión" de la tesis del tribunal colegiado del medio de difusión oficial. Además, le dio vista al Consejo de la Judicatura para que, en caso de ser necesario, iniciara con el procedimiento administrativo sancionatorio en contra de los magistrados.

El control sustantivo vertical -del inferior al superior- de la jurisprudencia se debatió de nuevo entre dos tribunales colegiados. Un colegiado argumentó que la jurisprudencia es una fuente formal que confirma, suple o interpreta un

10 Varios 912/2010, José Ramón Cossío Díaz, 14 de julio de 2011.

11 C.T. 61/2011, Luis María Aguilar Morales, 22 de junio de 2011, p. 33. (cursivas añadidas). Cfr. CPEUM, artículo 123 B XIII [2].

12 C.T. 61/2011.

13 Primer Tribunal Colegiado en Materia Administrativa del Cuarto Circuito, A.I. R. 557/2011, Sergio Eduardo Alvarado Puente, 14 de octubre de 2011, p. 69.

14 A. D. R, 2126-2012, Margarita Beatriz Luna Ramos, 21 de noviembre 2012, pp. 49-50. 
texto, por lo que puede ser sometida a un "escrutinio constitucional"15. El colegiado inaplicó una jurisprudencia de la primera sala que había identificado los hechos que constituían el tipo penal de contrabando presunto. A decir de la sala, estos hechos incluían "que se encuentren" vehículos extranjeros sin la documentación, sin que hubiera necesidad de demostrar que se introdujo el vehículo ${ }^{16}$. El colegiado consideró que esta jurisprudencia violaba el principio de presunción de inocencia y ordenó la absolución del inculpado.

El pleno de la SCJN terminó este debate acerca del control vertical. La mayoría sostuvo que el derecho a la seguridad jurídica implica que la jurisprudencia es "insoslayable y de aplicación inexcusable"17. El pleno incluso llegó a afirmar que los colegiados no están facultados para "reinterpretar"18 la jurisprudencia. La mayoría subrayó que eso no implicaba que la jurisprudencia fuera estática, pero sí que la SCJN era la única facultada para revisar su jurisprudencia. Esto puede suceder de dos maneras, primero, cuando la corte resuelve un caso concreto en el que modifica o abandona jurisprudencia. En segundo lugar, a través del mecanismo de sustitución de jurisprudencia en el que los inferiores acatan la jurisprudencia del superior y después de resolver el caso, le sugieren que abandone su criterio en un proceso abstracto.

Sin embargo, hubo un voto concurrente y dos votos disidentes. En voto concurrente, un ministro afirmó que la aplicabilidad tiene que ver con las condiciones que se dan para aplicar una norma mientras que la desaplicación tiene que ver con la validez de una norma ${ }^{19}$. Según el ministro, se podría decir que, una jurisprudencia de legalidad no es aplicable a un caso constitucional porque se trata de cuestiones jurídicas diversas. El primer disidente subrayó que la jurisprudencia debía ser ponderada caso por caso para elegir el criterio más beneficioso, en acatamiento del principio pro persona ${ }^{20}$. El otro argumentó que, si los criterios jurisprudenciales son normas que los intérpretes adscriben a una

15 Octavo Tribunal Colegiado de Circuito del Centro Auxiliar de la Tercera Región, A.D.122/2013, Elba Sánchez Pozos. 25 de abril de 2013, p. 38.

16 C.T. 158/2004, Juan Silva Meza, 22 de junio 2005.

17 C.T. 299/2013, Jorge Mario Pardo Rebolledo, 14 de octubre de 2014, p. 32.

18 Ibidem, p. 25.

19 Arturo Zaldívar Lelo De Larrea, (voto concurrente).

20 Juan N. Silva Meza, (voto particular). 
disposición, entonces es posible que las interpretaciones sean interpretables. ${ }^{21}$ Luego, si el proceso de interpretación puede derivar en normas jurisprudenciales que sean inconstitucionales, debe haber un mecanismo para impugnar esta norma, aun si el superior puede confirmar o revertir tal decisión.

Curiosamente, el ministro que defendía el control vertical de la constitucionalidad de la jurisprudencia, después fue el mayor crítico cuando el Tribunal Electoral del Poder Judicial Federal (TEPJF) ejerció una suerte de control horizontal. El TEPJF es la máxima autoridad judicial electoral en el país, con excepción del control abstracto que es ejercido por la SCJN. La sala superior del TEPJF consideró una jurisprudencia de la SCJN acerca de los principios de representación proporcional a nivel municipal, pero decidió no seguirla pues no materializaba el principio constitucional de pluralismo político. ${ }^{22}$ El desafío llegó a la corte vía unificación jurisprudencial y en la sentencia confirmó que debía prevalecer la jurisprudencia de la SCJN23. El ministro que había defendido el control de los colegiados ahora consideró que "la condición de seguridad es por la máxima jerarquía de este tribunal"; y ese "es un criterio absoluto" ${ }^{24}$.

La mayor objeción en contra del control de la constitucionalidad de la jurisprudencia en México se sustenta en el principio de jerarquía, no de seguridad jurídica. Ultimadamente, la SCJN sí puede modificar sus criterios, incluso de manera retroactiva. En realidad, el problema radica en que un órgano inferior cuestione al superior. Esto parecería acabar con una de las posibles concepciones de la jurisprudencia fundada en el principio de jerarquía: el precedente vertical vincula al inferior so pena que el superior pueda revocar la decisión, sancionar al juzgador o incluso inhabilitarlo.

\subsection{Colombia: El control excepcional de la jurisprudencia por expansión de competencias}

La CCC ha aceptado que, en casos excepcionales, cuenta con competencia para ejercer una suerte de control horizontal de la jurisprudencia de otras cortes supremas, es decir, el Consejo de Estado y la Corte Suprema. En la sentencia

21 José Ramón Cossío Díaz, (voto particular), 11-16, 23.

22 SUP-JDC-567/2017, Indálfer Infante Gonzales, 11 de octubre de 2018.

23 C.T. 382/2017, Alfredo Gutiérrez Ortiz Mena, 8 de noviembre de 2018.

24 Sesión pública ordinaria del Pleno de la SCJN, 6 de noviembre de 2018, p. 57. 
C-1436-00, a pesar de no ser una facultad expresamente reconocida en la Constitución, la CCC estableció que se pueden impugnar, en control abstracto, no solo las disposiciones sino también las interpretaciones plausibles que se derivan de ellas ${ }^{25}$.

Después, en la C-557-2001, se vinculó el control de la constitucionalidad de la jurisprudencia con la doctrina del derecho viviente ${ }^{26}$. La corte estableció que, si bien la acción de inconstitucionalidad es un proceso abstracto, esto no implica que se ignore el contexto de cómo ha vivido la norma ${ }^{27}$. Luego, es necesario tomar en cuenta las dimensiones lingüísticas y sociales para analizar cuál es el significado que los intérpretes, especialmente las cortes supremas, han adscrito a una disposición.

Poco después, en la C-426-02, la CCC, declaró la inconstitucionalidad de la jurisprudencia del Consejo de Estado. La jurisprudencia del Consejo condicionaba la acción simple de nulidad contra actos generales, y la admitía solo en casos excepcionales contra actos concretos siempre cuando comprometieran el orden público, social o económico del país. Con base en los derechos de debido proceso y acceso a la justicia, la CCC declaró inconstitucional la jurisprudencia por agregar requisitos que no se encontraban en la ley ${ }^{28}$. La corte aseguró que interpretaciones "excesivamente formalistas" 29 , como la del Consejo de Estado, podían convertirse en obstáculos para ejercer el derecho a la justicia.

El Consejo de Estado respondió desafiando a la CCC ratificando su anterior doctrina ${ }^{30}$. Según el Consejo, la CCC estaba invadiendo la competencia del legislador al reformar la disposición vía interpretación judicial. Además, consideró que la CCC solo era competente para controlar el contenido de "leyes", no de la jurisprudencia.

A pesar de esta tensión, la CCC volvió a declarar inconstitucional la jurisprudencia del Consejo. En la C-207-03 la corte declaró inconstitucional la jurisprudencia que había determinado que el recurso extraordinario en contra de la pérdida de investidura de congresistas solo era procedente a partir de la

25 C-1436-00, Alfredo Beltrán Sierra, 25 de octubre de 2000, VI, 3.

26 Sobre el derecho viviente véase, ZAGREBELSKY (2008).

27 C-557-01, Manuel José Cepeda Espinosa, 31 de mayo de 2000, VI, 5.1.

28 C-426-02, Rodrigo Escobar Gil, 29 de mayo de 2002, 7 y 7.15.

29 Ibídem, pp. 6,10.

30 Consejo de Estado, Sala Plena, IJ-30-2003, Manuel Santiago Urueta Ayola, 4 de marzo de 2003, VI 2.3. 
vigencia de la ley y no de manera retroactiva ${ }^{31}$. La CCC no encontró fundamento constitucional para distinguir entre congresistas que perdieron su investidura antes de la vigencia de la ley y después, por lo que se violaban, entre otros, el derecho a la igualdad y el derecho a la justicia.

Más recientemente, en la C-304-13 la CCC insistió en el carácter excepcional de este tipo de control que requiere una mayor carga argumentativa que el control tradicional sobre leyes ${ }^{32}$. Esta carga argumentativa adicional se da, según la corte, en base a dos principios: autonomía interpretativa judicial y competencia. La autonomía judicial se ha interpretado como una cierta deferencia hacia las cortes ordinarias en su facultad de determinar "el sentido autorizado de los textos legales" 33 . Mientras que el principio de competencia se ha comprendido como la necesidad de distinguir entre la facultad de la CCC de realizar control constitucionalidad y la de las cortes ordinarias de interpretar leyes.

La corte recopiló los cinco requisitos que debe tener una demanda de inconstitucionalidad en contra de la jurisprudencia, desarrollados en más de una década. Primero, debe especificarse la norma que se ha adscrito a la disposición, es decir, distinguir el texto de la interpretación judicial. En segundo lugar, debe haber certeza en cuanto a la norma. En tercer lugar, los argumentos deben ser puntuales, no vagos o abstractos. En cuarto lugar, la interpretación debe implicar un problema de relevancia estrictamente constitucional, no legal o académico. Finalmente, se insistió que la norma debe haber sido reiterada y consolidada, ya que un solo precedente, por regla general, no establece jurisprudencia.

En el caso colombiano el principio más relevante no es el de jerarquía sino el de competencia. La corte ha acudido a este principio de competencia para justificar un trato diferenciado entre el control de leyes y el de jurisprudencia. No obstante, para los escépticos, esto es una expansión de sus competencias más allá de lo previsto por la constitución. Además, la expansión de competencias de la CCC, simultáneamente, reduce las de otras cortes supremas. Por eso, la CCC ha insistido en el carácter excepcional de este control.

31 C-207-03, Rodrigo Escobar Gil, 11 de marzo de 2003. Invalidando Sala Plena, REVPI-005, Mario Alario Méndez, 10 de octubre de 2000.

32 C-304-13, Gabriel Eduardo Mendoza Martelo, 22 de mayo de 2013, 3.2 y VII.

33 C-569/04. Rodrigo Uprimny Yepes, 8 de junio de 2004, 13. La autonomía judicial se infiere de los artículos 228 y 230 de la Constitución. 


\section{RECONSTRUCCIÓN ANALÍTICA DEL CONTROL}

DE LA CONSTITUCONALIDAD DE LA JURISPRUDENCIA

\subsection{Cuatro puntos acerca del control de la constitucionalidad de la jurisprudencia}

Si el control de la constitucionalidad de las leyes se trata de una revisión judicial a las disposiciones generales emitidas por el ejecutivo y legislativo por presuntas violaciones a derechos fundamentales o de separación de poderes que puede derivar en su invalidación general o inaplicación para un caso concreto. Entonces, ¿en qué distingue o asemeja el control de la constitucionalidad de la jurisprudencia de este control de leyes?

Una postura del positivismo decimonónico, pero aún defendida en algunos círculos, es que mientras los legisladores crean derecho, los jueces se limitan a interpretarlo ${ }^{34}$. Sin embargo, en un sentido general, los legisladores también interpretan el derecho y aprueban enunciados que se supone transmiten la voluntad popular. En sentido más concreto y pragmático, los legisladores interpretan sus disposiciones y anticipan interpretaciones que podrían ser controvertidas por inconstitucionales ${ }^{35}$. Por lo tanto, es necesario contrastar ambos controles para entender la diferencia específica del control de la jurisprudencia.

Esta comparación entre control de leyes y control de jurisprudencia se puede subdividir en cuatro rubros, a saber: (i) nacimiento de la fuente controlada, (ii) función de la fuente controlada, (iii) sujetos que intervienen y (iv) efectos de una declaración de inconstitucionalidad.

Para responder estas preguntas se utilizará la conocida distinción entre disposición y norma ${ }^{36}$. La disposición es el texto previo a la interpretación que se encuentra en las constituciones o leyes. En cambio, la norma es un significado -de los muchos posibles- que mediado por métodos interpretativos, los hechos del caso, e influido por ideologías personales, un intérprete le adscribe a ésta. Es decir, hay interpretación en cuanto al contenido normativo, e interpretación fáctica para determinar si los hechos del caso se subsumen o no dentro de dicho

34 Zertuche (1990); Beever (2013).

35 STONe \& SweET (2000), p. 13.

36 Crisafulli (2011), p. 67. 
contenido ${ }^{37}$. De esta manera, el derecho judicial esta conformado por normas que los órganos judiciales adscriben a un texto constitucional, legislativo, ejecutivo o de otros órganos en vista de los hechos o hipótesis del caso ${ }^{38}$.

Esta distinción no implica adoptar una postura escéptica radical en cuanto a la interpretación. Esta postura implicaría que los textos significan lo que sea que los intérpretes digan. Pero esa no es la postura que la SCJN ni la CCC han adoptado al utilizar la distinción ${ }^{39}$. Esta postura solo indica que hay discreción y creatividad en la interpretación judicial, aunque también, puede haber consenso acerca de la interpretación de una determinada disposición ${ }^{40}$, o al menos consenso de lo que no se puede inferir.

En primer lugar, es necesario determinar cuándo nace la fuente. Es evidente que una disposición legislativa nace cuando se promulga y pública la disposición en el medio oficial. Hay que distinguir el nacimiento de la fuente, de la obligación de seguirla. Esto puede variar, por ejemplo, por la vacatio legis. En cuanto a la norma adscrita, ésta nace cuando se elige una de las posibles interpretaciones dentro del abanico de posibilidades. En cambio, la obligación de seguir esa norma dependerá del derecho positivo vigente que establezca cuando hay jurisprudencia obligatoria (p. ej. La necesidad de reiteración). Mientras no exista, tanto la norma adscrita como la obligación, al menos prima facie, de seguirla en todos los casos análogos no puede haber control de la jurisprudencia sino un mero control de interpretación.

En segundo lugar, ¿̨cuál es la función de la fuente controlada? la función tradicional de las disposiciones legislativas es guiar la conducta humana. Las normas adscritas también cumplen esta función. Pero, además, las normas adscritas judicialmente pueden declarar, corregir, o integrar el texto interpreta$\mathrm{do}^{41}$. Las primeras normas adscriben el significado lingüístico más inmediato, mientras que las correctoras se refieren a reducir o a ampliar el alcance de la disposición, y las integradoras colman lagunas o resuelven tensiones más allá del texto interpretado.

\footnotetext{
37 Guastini (2012), pp. 28-29.

38 Bernal (2007), p. 104.

39 C-038-2006, Humberto Antonio Sierra Porto, 1 de febrero de 2006; C.T. 293/2011, Arturo Zaldívar Lelo de Larrea, 3 de septiembre de 2013.

40 SHECARIA (2015).

41 Guastini (1999), Cap II.
} 
En tercer lugar, ¿quién interviene en este control? el control de la constitucionalidad de leyes implica una interacción entre el poder judicial y el legislativo, mientras que el control de la jurisprudencia se da entre distintos órganos judiciales. En el control de la jurisprudencia hay una interacción entre la jerarquía de las fuentes y la jerarquía de intérpretes. Una norma adscrita al texto constitucional es superior a cualquier fuente infra-constitucional. Luego, una norma adscrita a las leyes será del nivel coordinado a esta pero inferior al texto constitucional. Esta jerarquía de las normas adscritas interactúa con la jerarquía del órgano que interpreta la disposición. Una corte constitucional puede compartir la cúspide del poder judicial con otras cortes por lo que hay relación judicial de coordinación. Sin embargo, toda vez que la constitución es una norma superior a las leyes, cuando los hechos del caso sean tanto una cuestión constitucional como legal, entonces, la corte constitucional será superior a la corte suprema. De manera similar, la jurisprudencia constitucional de un órgano intermedio podría colisionar con la jurisprudencia de legalidad de un órgano superior.

En cuarto lugar, es esencial identificar los efectos que podría tener una declaración de inconstitucionalidad de la jurisprudencia. En el caso del control de constitucionalidad de leyes una disposición se declara inconstitucional cuando todas y cada una de las posibles normas que se pueden inferir son, claramente, inconstitucionales o cuando una posible interpretación semánticamente plausible es constitucionalmente dañina. Es decir, se "sanciona" con nulidad la decisión textual del legislador al elegir ciertas palabras. En cambio, si una norma plausible es constitucional y otra no lo es, entonces, de acuerdo con el principio de interpretación conforme, se elige la norma constitucional. Es decir, se sanciona al intérprete, y no al legislador, por la elección interpretativa de una norma inconstitucional cuando había posibilidades de "salvar" 42 la constitucionalidad de la disposición. En el control de la constitucionalidad de leyes existen al menos dos escenarios. En el modelo concentrado se puede expulsar una disposición legislativa con efectos generales. En el modelo difuso se puede desaplicar una norma inferida de la ley solo para el caso concreto y sentar el precedente de que dicha disposición es inconstitucional para que el legislador reforme o derogue el texto. Entonces, un efecto sería eliminar la norma del método de difusión

42 Vermeule (1997). 
por el que se publica en la jurisprudencia. El otro efecto, sería desaplicar la jurisprudencia en el caso concreto.

\subsection{Normas adscritas declaratorias, correctoras e integradoras}

La distinción disposición/norma, también, es útil para comprender más cabalmente qué es exactamente lo que controla el control de la constitucionalidad. De manera más precisa, nos ayuda a determinar si es posible disociar entre el texto interpretado y su interpretación.

A la luz de esta distinción, y en relación con lo mencionado en la anterior subsección, se puede hablar de tres tipos de normas adscritas, a saber, declaratorias, correctoras o integradoras. Una norma declaratoria simplemente adscribe el significado más convencional o anticipado que pudiera esperarse. De ahí que, cuando se considera inconstitucional, en realidad, el legislativo es el órgano responsable por expedir la disposición, no el judicial por interpretarla en determinado sentido. En el ejemplo mencionado del delito de contrabando presunto en México, si se entiende que la única interpretación semánticamente plausible es que no era necesario acreditar la introducción del vehículo, entonces, el control realmente recayó sobre la disposición legislativa.

Una norma correctora se aleja del significado más inmediato y pueden ser restrictivas o expansivas. La restrictiva da una interpretación más limitada de la que se pudiera esperar. La expansiva da una interpretación más amplia. Un ejemplo, de interpretación restrictiva, fue la decisión del Consejo de Estado de Colombia en restringir el acceso a la acción simple de nulidad.

Finalmente, una norma integradora colma lagunas o resuelve tensiones normativas, más allá del texto. Los intérpretes pueden detectar lagunas normativas -algo que el derecho debe regular y no regula, y lagunas axiológicas- algo que el derecho regula deficientemente desde el punto de vista político o moral ${ }^{43}$. Luego, los intérpretes pueden colmar estas lagunas mediante autointegración-acudiendo a otra disposición de la misma ley, o mediante heterointegración- acudiendo a otra fuente, normalmente superior, para colmar la laguna ${ }^{44}$. El ejemplo del trato diferenciado a trabajadores es una norma adscrita heterointegradora. A

43 Alchourron y Bulygin (1987), p. 147.

44 Carnelutti (2003), pp. 122-131. 
decir del colegiado, la SCJN debió de haber detectado la laguna y colmarla con normas convencionales que forman parte del bloque de constitucionalidad.

En el caso de normas correctoras e integradoras, hay interpretación creativa. Esta interpretación es susceptible de violar derechos o principios constitucionales. Cuando, además, hay obligación de seguir esa norma adscrita en casos análogos, la violación trasciende el caso particular. De ahí la posibilidad conceptual de que la jurisprudencia, y no la ley, sea la fuente que viola la constitución.

\section{UNA DEFENSA DEL CONTROL DE LA CONSTITUCIONALIDAD}

DE LA JURISPRUDENCIA

El control de la constitucionalidad de la jurisprudencia trae consigo distintas implicaciones normativas, según los diseños institucionales de cada país.

En México, a decir de los escépticos, aceptar el control semi-difuso de la constitucionalidad de la jurisprudencia de legalidad de la SCJN parece insinuar una rebelión judicial. Los inferiores podrían desafiar la jurisprudencia del superior, argumentando que viola fuentes superiores como la constitución o los tratados que forman parte del bloque de constitucionalidad. Esto podría motivar una cacofonía jurisprudencial donde los órganos inferiores acaban con la función de la corte como órgano de cierre. La regla del precedente vertical se difuminaría por completo. Sin embargo, rechazar este control implica que, la única manera en que la ciudadanía pueda impugnar una jurisprudencia sea con la suerte de que su asunto llegue a la SCJN.

En Colombia, en cambio, el control concentrado de la jurisprudencia implica una expansión de sus facultades entre iguales. Por ello, la CCC ha atemperado el uso del control estableciendo cargas de argumentación particularmente gravosas. Así, se ha justificando la expansión de la competencia solo en casos excepcionales. Además, esta expansión no ha sido unidireccional. La CCC también ha aceptado, al menos en teoría, que las otras cortes supremas desafíen el precedente constitucional en casos excepcionales y mediante una “justificación suficiente" 45 . Así, la competencia se entiende como un principio relativamente elástico. La CCC puede ampliar su competencia resolviendo asuntos no previstos por el texto constitucional, pero también, puede reducirla o compartirla para que otros órganos expandan sus respectivas competencias.

45 T-309-15, Jorge Ignacio Pretelt Chaljub, 30 de septiembre de 2015, 4.4.1; C-621-15, Jorge Ignacio Pretelt Chaljub, 30 de septiembre de 2015. 
El contraste de los casos revela distintos entendimientos de la obligación de seguir la jurisprudencia. En México, se entiende como una regla categórica dirigida a los órganos inferiores a aplicar la norma adscrita en casos similares. Por eso se llegó a decir que la obligación de seguirla era "inexcusable" o de "criterio absoluto". En cambio, en Colombia, se entiende como una regla prima facie que, al menos en casos excepcionales, puede llegar a ser desafiada, más no ignorada.

Una manera de comprender el control de la constitucionalidad de la jurisprudencia puede ser a la luz de los principios formales. A diferencia de los principios sustantivos, como la libertad de expresión, los principios formales son "mandatos de optimización que exigen que las decisiones autoritativas sean respetadas en la mayor medida posible" 46 . Éstos incluyen el principio de igualdad, seguridad jurídica, jerarquía y competencia.

Usualmente se apela a estos principios para defender el control de la constitucionalidad, principalmente, el que usa el método de la ponderación, de la crítica contramayoritaria. ${ }^{47}$ En cambio, aquí, se apela para justificar la vinculación relativa al derecho judicial. Los procesos judiciales son un procedimiento deliberativo de autoridad competente que culmina con la resolución y, genera la presunción que casos futuros similares serán tratados de manera coherente. Esta vinculación no es absoluta, sino prima facie. Las cortes supremas pueden cambiar sus propios precedentes, aún si esto afecta el principio de seguridad jurídica. Cualquier órgano judicial puede crear una excepción a la regla al distinguir un caso por diferencias jurídicamente relevantes, aun si esto afecta el principio de igualdad. En ambos casos los principios formales imponen una carga de argumentación que permite no seguir el precedente.

El principio formal más importante para el caso colombiano, dada la fragmentación del poder judicial en tres cortes supremas, es el de competencia. El principio de competencia faculta a un órgano para resolver cierto tipo de casos según, su especialización por materia. En este caso hay una tensión entre la competencia de la CCC como corte constitucional interpretando leyes y otras cortes de legalidad. La CCC expandió su competencia para controlar la jurisprudencia de legalidad de otras cortes supremas. En respuesta, el Consejo de Estado cuestionó a la CCC por arrogarse facultades, lo que perjudica el

46 Portocarrero Quispe (2016), p. 28.

47 Alexy (2002). p. 417. 
principio de legalidad y la autonomía interpretativa del Consejo. Siguiendo a Matthias Klatt, los conflictos de competencia pueden ser formales o materiales ${ }^{48}$. Son formales cuando dos órganos se ostentan como competentes para emitir una decisión, sin importar si las decisiones difieren o no. En cambio, son materiales cuando las decisiones son incompatibles. El conflicto solo es material cuando sus interpretaciones son incompatibles.

Este mecanismo permite que la expansión de la competencia no sea unidireccional sino dialógica. La CCC está facultada para analizar la jurisprudencia de legalidad de las otras cortes, pero éstas, también, pueden llegar a cuestionar la jurisprudencia de constitucionalidad. O sea, la CCC expande su competencia para cuestionar a otros órganos judiciales, pero al mismo tiempo, reconoce que otros órganos judiciales, del mismo o menor rango, la cuestionen. Con todo, habría que determinar empíricamente hasta qué grado la CCC ha aceptado el cuestionamiento de otras cortes supremas y entablado un verdadero diálogo.

Este enfoque puede explicar el funcionamiento del control de la constitucionalidad de la jurisprudencia en Colombia. Cuando exista tensión entre dos órganos competentes se puede maximizar la competencia de cada uno según sea el caso. En casos de una violación grave a normas constitucionales, la competencia de la CC se maximiza por encima de la de las cortes supremas de legalidad sin eliminar definitivamente su competencia.

La principal diferencia entre el caso colombiano y el mexicano es la carencia de una corte constitucional en el segundo. La SCJN es al mismo tiempo la cúspide del poder judicial en materia de legalidad y tribunal constitucional. Esto hace que el único mecanismo potencial para que particulares impugnen una norma jurisprudencial sea el juicio de Amparo. No obstante, la SCJN rechazó este tipo de control ya que, hubiera permitido que órganos judiciales inferiores cuestionaran la jurisprudencia del superior.

Una incógnita, aún no respondida por la SCJN, es si se puede realizar control abstracto constitucionalidad de la jurisprudencia. Después de todo, la jurisprudencia ordinaria es una norma abstracta, impersonal y general que puede violar la constitución y sería la misma SCJN quien resolviera la cuestión. Sin embargo, este control solo estaría al acceso de autoridades, dejando indefensos a los particulares.

48 Klatt (2015), pp. 199-200. 
El enfoque de los principios formales, discutido previamente, también sirve para sugerir un cambio en el caso mexicano. Así como la CCC moderó el alcance del control concentrado de la jurisprudencia, la SCJN podría haber reconocido el control semi-difuso. Esto requeriría una carga de la argumentación extra a cargo del tribunal colegiado pues le permitiría expandir su competencia para controlar no solo la constitucionalidad de leyes, sino de la jurisprudencia de legalidad. Nadie niega la primacía de la SCJN en la jerarquía de intérpretes judiciales, pero tampoco se puede negar que la jurisprudencia de legalidad de la SCJN puede contradecir normas superiores.

Este tipo de control, también, podría generar un diálogo entre la SCJN y los colegidos. El superior podría confirmar la decisión, aceptando que la decisión previa no tomó en cuenta principios constitucionales en juego, o bien, podría revertir la decisión del inferior. Este diálogo puede ser similar al que llevan a cabo los órganos judiciales inferiores cuando distinguen casos ${ }^{49}$. Así, un tribunal de cualquier jerarquía puede negarse a seguir un precedente cuando haya diferencias fácticas entre el precedente y el caso por resolver. En efecto, como observan Lundmark y Waller, cuando un órgano judicial distingue un caso, lo que está haciendo es afirmar que si la corte original resolviera hoy el caso, en realidad resolvería de manera similar a como lo hizo el posterior ${ }^{50}$.

Los colegiados podrían maximizar su competencia sin anular la jerarquía de la SCJN. Éstos analizan la constitucionalidad de la jurisprudencia, aun sin competencia expresa en la constitución y las leyes. Pero esta expansión de su competencia no implica un menoscabo definitivo en la autoridad de la SCJN. El colegiado puede brindar razones de relevancia constitucional que la jurisprudencia ordinaria omitió. Por su parte, la SCJN podría confirmar o no la distinción del caso original.

En este escenario la carga de la argumentación que permite desafiar el principio de jerarquía no es insuperable. La corte puede haber ignorado fuentes de nivel constitucional. Esto se vuelve particularmente relevante en países, como Colombia y México, que reconocen derechos humanos de convenciones internacionales como derechos constitucionales.

49 Usualmente se habla de "falta de aplicabilidad" pero también se utiliza la terminología anglosajona de "distinguishing” en algunos precedentes, p. ej., A.D.R. 5601-2014, Arturo Zaldívar Lelo de Larrea, 17 de junio de 2015.

50 Lundmark y Waller (2016), pp. 451-452. 
A la luz de este enfoque de los principios formales se podría sacar provecho de la naturaleza discursiva del precedente. Los principios formales imponen la obligación presuntiva de seguir el precedente pero es derrotable. La carga de la argumentación estará a cargo del órgano que desafía y, a mayor sea el desafío mayor será la carga de argumentación.

Además, este entendimiento del control de la constitucionalidad de la jurisprudencia coincide con una creciente gradualidad de las fuentes en México y Colombia, en contraposición a una división categórica. En primer lugar, las normas se entienden no solo como reglas que deben ser aplicadas, sino como principios que deben maximizarse o que pueden ponderarse caso por caso. Esto aplica tanto a principios sustantivos como formales. En segundo lugar, el principio pro persona cuestiona la jerarquía categórica entre fuentes. El criterio definitivo ya no es el de superioridad sino el de la norma más beneficiosa. En tercer lugar, la división entre legalidad y constitucionalidad se ha vuelto borrosa. Las constituciones son cada vez más generosas en cuanto a derechos y más detalladas en cuanto a principios orgánicos. El texto constitucional se ha ampliado con los Tratados Internacionales de Derechos Humanos. Esto hace que casi cualquier interpretación judicial sea de relevancia constitucional. En cuarto lugar, la jurisprudencia es la fuente gradual por excelencia. En ocasiones excepcionales, un precedente singular puede tener una gran fuerza vinculante, sin embargo, por regla general, la jurisprudencia se construye paulatinamente a través del análisis reiterado de casos similares. La obligación de los órganos judiciales es tomar en cuenta la jurisprudencia, pero si cuentan con argumentos de peso para cuestionarla, deben hacerlos explícitos.

\section{CONCLUSiOnes}

Este artículo ha analizado el control de la constitucionalidad de la jurisprudencia de legalidad. Es posible que un intérprete judicial -sea de la jerarquía que sea- adscriba una norma a una disposición infra-constitucional que viole normas superiores y que esta interpretación se aplique a una pluralidad de casos $y$ es deseable que existan controles sobre esta norma.

El análisis ha arrojado resultados acerca de la naturaleza de la jurisprudencia como fuente jurídica. La jurisprudencia está conformada por decisiones interpretativas de órganos judiciales que adquieren un estatus autónomo respecto al texto interpretado en virtud de los principios formales de seguridad jurídica, igualdad, competencia y jerarquía. No obstante, este estatus no debe ser absoluto. 
El control de la jurisprudencia se da cuando la interpretación creativa judicial expande o reduce el alcance originario violando derechos constitucionales. Deben existir controles concentrados o semi-difusos que permitan maximizar la competencia de algunos órganos para cuestionar la jurisprudencia de otros, sin eliminar la competencia de otros.

A su vez, el análisis implica cuestiones de relevancia práctica en la interacción entre órganos judiciales. El control de la constitucionalidad de la jurisprudencia genera una tensión entre distintos órganos judiciales. Esta tensión es particularmente obvia en el caso mexicano donde los tribunales colegiados desafiaron a la Suprema Corte. No obstante, esta fricción no necesariamente es insuperable. Cuando existe una interpretación legal vinculante de la corte, es posible que el colegiado apele a la constitución como norma superior para contrarrestar la asimetría de jerarquías entre intérpretes. Además, el desafío deberá ir precedido de una carga de la argumentación, como se vio en el caso colombiano y podrá ser confirmado o rechazado por el superior.

El control de la constitucionalidad de jurisprudencia puede dar lugar a un diálogo dentro del poder judicial, que no implica abandonar la naturaleza de los precedentes como reglas vinculantes. Los principios formales otorgan a las normas adscritas un estatus superior al de meras interpretaciones aisladas o hipotéticas. No obstante, se puede crear un diálogo horizontal entre cortes supremas con distinta competencia o un diálogo de abajo hacia arriba en la construcción intersubjetiva de la jurisprudencia.

\section{Bibliografía CitADA}

Alchourron, Carlos E., Bulygin, Eugenio (1987): Introducción a la Metodología de las Ciencias Jurídicas y Sociales, (Buenos Aires, Editorial Astrea).

AlEXY, Robert (2002): A Theory of Constitutional Rights (J. Rivers, Trad.): (Oxford Oxford, University Press).

BARRERA, Javier (2014): "La posición de la jurisprudencia en el sistema de fuentes del derecho colombiano”, en Saber, Ciencia y Libertad, (Vol. 9 No 2), pp. 57-70.

BÉAL-LONG, Julien (2016): "Le contrôle de l'interprétation jurisprudentielle constante en QPC", en Revue française de droit constitutionnel, (Vol. 1 No 105), pp. e1-e28.

Bernal, Carlos. (2007): El principio de proporcionalidad y los derechos fundamentales ( $3^{\mathrm{a}} \mathrm{ed}$.) (Madrid, Centro de Estudios Políticos y Constitucionales). 
Bushell, Allison A., \& Hogg, Peter W. (1997). "The Charter dialogue between courts and legislatures (or perhaps the Charter of Rights isn't such a bad thing after all”, en Osgoode Hall Law Journal (Vol. 35 No 1), pp. 75-124.

Carnelutti, Francesco (2003): Teoría General del Derecho (Carlos G. Posada trad, (Granada, Editorial Comares).

Crisafulli, Vezio (2011): “Disposición (y norma)", en Disposición y norma (Lima, Palestra), pp. 67-109.

Dixon, Rosalind (2012): "Weak-Form Judicial Review and American Exceptionalism", en Oxford Journal of Legal Studies (Vol. 32 No 3, pp. 487-506.

Gardbaum, Stephen (2002): "The New Commonwealth Model of Constitutionalism", en American Journal of Comparative Law, (Vol. 49), pp. 707-760.

GÓmorA, Sandra (2017): "La posibilidad conceptual y el argumento histórico en torno al estudio del precedente", en Precedente (Vol. 11), pp. 137-185.

GuASTINI, Riccardo (1999). Estudios sobre la interpretación jurídica (M. Gascón y M. Carbonell, (México, UNAM).

GUASTINI, Riccardo (2012): "El escepticismo ante las reglas replanteado", en Discusiones. No 11, pp. 27-57.

Kelsen, Hans (1942): "Judicial Review of Legislation: A Comparative Study of the Austrian and the American Constitution", en The Journal of Politics (Vol. 4 No 2), pp. 183-200.

KLATT, Matthias (2015): "Balancing Competences: How Institutional Cosmopolitanism Can Manage Jurisdictional Conflicts", en Global Constitutionalism, (Nol. 4 No 2), pp. 195-226.

Llewellyn, Karl N. (1960): The Common Law Tradition: Deciding Appeals (Boston, Little, Brown and Company).

López, Diego (2006): El derecho de los jueces (2ª ed.), (Bogotá, Legis).

LÓPEZ, Diego (2016): Eslabones del derecho: el deber de coherencia con el precedente judicial, (Bogotá, Legis).

Lundmark, Thomas; Waller, Hellen (2016): "Using Statutes and Cases in Common and Civil Law", en Transnational Legal Theory (Vol. 704), pp. 429-469. Moral, Leonor (2002): El Precedente Judicial (Madrid, Marcial Pons).

PeCZENIK, Aleksander (1996): "Sui precedenti vincolanti de facto", en Ragion Pratica (Vol. 6), pp. 35-43.

Portocarrero, Jorge A. (2016): La ponderación y la autoridad en el derecho, (Madrid, Marcial Pons). 
Serna de la Garza, José María (2009): "The Concept of Jurisprudencia in Mexican Law”, en Mexican Law Review Vol. 2 No 1, pp. 131-145.

SheCaira, Fábio P. (2015): "Sources of Law Are Not Legal Norms", en Ratio Juris (Vol. 28 No 1, pp. 15-30.

Sierra, David (2016): "El precedente: un concepto", en Revista Derecho del Estado (Vol. 36), pp. 249-269.

Stone Sweet, Alec (2000): Governing with Judges: Constitutional Politics in Europe, (Oxford, Oxford University Press).

Tushnet, Mark (2003). "Alternative Forms of Judicial Review", en Michigan Law Review (Vol. 101 No 8), pp. 2781-2802.

Vermeule, Adrián (1997): "Saving Constructions", en Georgetown Law Journal (Vol. 85 No 6), 1945-1977.

Zagrebelsky, Gustavo (2008): "Realismo y Concreción del Control de Constitucionalidad de las Leyes en Italia”, en Estudios Constitucionales (Vol. 6 No 1), pp. 325-335.

ZERTUCHE, Héctor G. (1990): La Jurisprudencia en el sistema jurídico mexicano, (México, Editorial Porrua).

\section{JURISPRUDENCIA CITADA}

\section{Colombia}

C-1436-00, Alfredo Beltrán Sierra, 25 de octubre de 2000.

C-426-02, Rodrigo Escobar Gil, 29 de mayo de 2002.

C-207-03, Rodrigo Escobar Gil, 11 de marzo de 2003.

C-569/04. Rodrigo Uprimny Yepes, 8 de junio de 2004.

C-038-2006, Humberto Antonio Sierra Porto, 1 de febrero de 2006.

C-304-13, Gabriel Eduardo Mendoza Martelo, 22 de mayo de 2013.

C-621-15, Jorge Ignacio Pretelt Chaljub, 30 de septiembre 2015.

C-136-17, Alejandro Linares Cantillo, 1 de marzo de 2017.

T-309-15, Jorge Ignacio Pretelt Chaljub, 30 de septiembre de 2015.

Consejo de Estado, Sala Plena, IJ-30-2003, Manuel Santiago Urueta Ayola, 4 de marzo de 2003.

Consejo de Estado, Sala Plena, REVPI-005, Mario Alario Méndez, 10 de octubre de 2000. 


\section{Francia}

2010-39 QPC de 6 de octubre de 2010.

\section{México}

Pleno, Varios 912/2010, José Ramón Cossío Díaz, 14 de julio de 2011.

Pleno, C.T. 293/2011, Arturo Zaldívar Lelo de Larrea, 3 de septiembre de 2013.

Pleno, C.T. 299/2013, Jorge Mario Pardo Rebolledo, 14 de octubre de 2014.

Pleno, C.T. 382/2017, Alfredo Gutiérrez Ortiz Mena, 8 de noviembre de 2017.

Primera Sala, C.T. 158/2004, Juan Silva Meza, 22 de junio de 2005.

Primera Sala, A.D.R. 5601-2014, Arturo Zaldívar Lelo de Larrea, 17 de junio de 2015.

Segunda Sala, C.T. 40/2000. Guillermo I. Ortiz Mayagoitia, 23 de agosto de 2002.

Segunda Sala, C.T. 61/2011, Luis María Aguilar Morales, 22 de junio de 2011. Segunda Sala, A.D.R. 2126/2012, Margarita Beatriz Luna Ramos, 21 de noviembre de 2012.

Primer Tribunal Colegiado en Materia Administrativa del Cuarto Circuito. A.I.R. 557/2011, Sergio Eduardo Alvarado Puente, 14 de octubre de 2011. Octavo Tribunal Colegiado de Circuito del Centro Auxiliar de la Tercera Región, A.D. 122/2013, Elba Sánchez Pozos, 25 de abril de 2013.

Sala Superior del Tribunal Electoral, SUP-JDC-567/2017, Indálfer Infante Gonzales, 11 de octubre de 2017.

\section{OtROS DOCUMENTOS}

Acuerdo general número 20/2013, de veinticinco de noviembre de dos mil trece, del pleno de la suprema corte de justicia de la nación, relativo a las reglas para la elaboración, envío y publicación en el semanario judicial de la federación y su gaceta, de las tesis que emiten la suprema corte de justicia de la nación, los plenos de circuito y los tribunales colegiados de circuito.

Contenido de la versión taquigráfica de la sesión pública ordinaria del pleno de la suprema corte de justicia de la nación, celebrada el martes 06 de noviembre de 2018 . 